\title{
VirtualMat: um ambiente virtual de apoio ao ensino de matemática para alunos com Deficiência Intelectual
}

Title: VirtualMat: a virtual environment to support the teaching of mathematical concepts for students with intellectual disability

Fernanda Francielle de Oliveira Malaquias

Universidade Federal de Uberlândia

fernandafrancielle@yahoo.com.br

\author{
Alexandre Cardoso \\ Universidade Federal de Uberlândia \\ alexandre@ufu.br
}

\author{
Edgard Afonso Lamounier Jr. \\ Universidade Federal de Uberlândia \\ lamounier@ufu.br \\ Cleusa Aparecida de Oliveira Santos \\ Universidade Federal de Uberlândia \\ cleusaaos@yahoo.com.br
}

Resumo Considerando-se que alunos com Deficiência Intelectual apresentam dificuldades para apreender conceitos matemáticos por métodos de ensino tradicionais e que são escassas as ferramentas voltadas para esses alunos, este artigo tem como objetivo apresentar o software VirtualMat, um ambiente virtual educativo desenvolvido especialmente para alunos com Deficiência Intelectual. $O$ software visa servir como ferramenta de apoio ao ensino de conceitos lógicomatemáticos, proporcionando variadas opções de organização cognitiva a respeito dos conceitos de classificação, discriminação, ordenação e sequenciação. $O$ software foi testado por alunos com Deficiência Intelectual matriculados em uma escola inclusiva e para avaliar a sua eficiência foi adotada uma abordagem tanto quantitativa quanto qualitativa. Os resultados apontam que o VirtualMat contribui significativamente para a aprendizagem dos alunos ao permitir o desenvolvimento do pensamento lógico-matemático de forma lúdica e ativa.

Palavras-Chave: Realidade Virtual, Deficiência Intelectual

\begin{abstract}
Considering that students with intellectual disability present difficult to apprehend mathematical concepts through traditional methods and that the tools aimed at these students are scarce, this paper aims to present the VirtualMat software, an educational virtual environment aimed specially at students with intellectual disability. The software is intended to serve as a support tool for the teaching of logical-mathematical concepts, providing varied options of cognitive organization on the concepts of classification, discrimination, ordering and sequencing. The software was tested by students with intellectual disability from an inclusive and in order to evaluate its efficiency it was adopted a quantitative and also a qualitative approach. The results indicate that VirtualMat contributes significantly to the students learning process by allowing the development of the mathematical reasoning in a playful and active way.
\end{abstract}

Keywords: Virtual Reality, Intellectual Disability 


\section{Introdução}

A matemática é uma disciplina utilizada em nossa vida todos os dias e em diversas situações. Mas, apesar de sua importância, a matemática sempre foi considerada uma disciplina complexa e de difícil compreensão por grande parte dos alunos.

Para alunos com Deficiência Intelectual esta realidade se torna ainda mais evidente, na medida em que estes possuem dificuldades para apropriar-se de elementos fundamentais para a apreensão de conceitos matemáti$\cos$.

Alunos com Deficiência Intelectual geralmente apresentam limitações nas habilidades que exigem atenção, memorização, compreensão de conceitos, generalização e abstração que são elementos fundamentais para aprendizagem escolar em geral e em específico da matemática [1] [2].

No entanto, apesar dessas limitações, sabe-se que se o aluno com Deficiência Intelectual for estimulado adequadamente, sendo assistido em suas necessidades educativas especiais por meio do uso de recursos diferenciados, ele irá se desenvolver em sua aprendizagem acadêmica [3].

A tecnologia computacional, por exemplo, é um recurso que pode ser utilizado como alternativa a instrumentos usados no cotidiano escolar (quadro, caderno, livro etc) e que deveria atender a esses alunos no âmbito escolar, promovendo a inclusão dos mesmos, independente de suas diferenças. O problema é que a maioria das tecnologias computacionais disponíveis está a serviço de pessoas com deficiência física, auditiva e visual [4].

Tal constatação motivou o desenvolvimento do software VirtualMat, apresentado nesse trabalho. Ele consiste em um Ambiente Virtual educativo que visa auxiliar o professor a explorar noções básicas de conceitos lógicomatemáticos, enquanto estratégia pedagógica. O sistema tem o intuito de proporcionar ao aluno com Deficiência Intelectual a prática de apreender as habilidades de classificar, discriminar, ordenar e seqüenciar, além de permitir que o professor trabalhe com os alunos diversos outros conceitos fundamentais da Matemática.

Estruturalmente, este trabalho está dividido em mais seis seções. Na segunda seção são apresentados os trabalhos relacionados ao uso de RV na educação especial. $\mathrm{Na}$ terceira são apresentadas as características dos alunos com deficiência intelectual bem como a aprendizagem de matemática por parte destes alunos. Em seguida tem-se a descrição do sistema VirutalMat, os aspectos metodoló- gicos vinculados à sua aplicação/teste e os resultados obtidos no artigo. A última seção contém as considerações finais e recomendações para pesquisas futuras.

\section{Realidade Virtual e Educação Es- pecial}

A Realidade Virtual (RV) pode ser definida como uma interface avançada para aplicações computacionais, que permite ao usuário se movimentar (navegar) e interagir em tempo real em um ambiente tridimensional [5].

A RV vem se disseminando rapidamente em várias áreas do conhecimento e se mostrando como uma ferramenta particularmente interessante para a educação [6]. Nesta área, a RV tem sido considerada como uma das possibilidades que as tecnologias da informação e da comunicação oferecem para trabalhar os conteúdos educativos visando atrair a atenção do aluno, interferindo positivamente na sua motivação para aprender e na retenção desse aprendizado [7]. Diversos autores, inclusive, apontam vantagens da utilização de técnicas de RV para fins educacionais [8] [6] [9].

Em particular, no âmbito da educação especial, vários resultados vêm fornecendo subsídios para que novas iniciativas sejam empreendidas [10] [11].

Em [10], por exemplo, foi apresentado um ambiente virtual denominado MemoZoo, que tem como objetivo apoiar a aprendizagem de Matemática por crianças com Transtorno de Déficit de Atenção e/ou Hiperatividade (TDAH). O MemoZoo é um "jogo da memória” de animais, tridimensional, situado em um jardim, onde o aluno pode realizar operações de adição enquanto participa do jogo. A fim de comparar a tecnologia de RV e a multimídia, a autora utilizou também outro software, sem Realidade Virtual. O resultado deste trabalho apresenta as vantagens da RV em relação à multimídia e aponta o grande potencial da RV como ferramenta de apoio para a realização de exercícios escolares de Matemática por crianças com TDAH.

[11] fizeram uma revisão da literatura apresentando diversas pesquisas sobre o uso de RV voltado para crianças com deficiência. Neste artigo foram citadas aplicações de RV desenvolvidas para crianças com problemas visuais, para crianças com autismo, para crianças com problemas auditivos, para crianças com deficiência física e para crianças com déficit de atenção e hiperatividade. Os autores também citam algumas aplicações desenvolvidas por eles, dentre elas o Virtual Shopping desenvolvido para alunos com autismo. 
No que se refere ao uso da tecnologia de RV para alunos com deficiência intelectual, a literatura é ainda limitada. A maior parte das aplicações da RV para pessoas com deficiência intelectual focam no treinamento de habilidades da vida diária, na reabilitação cognitiva ou no desenvolvimento de habilidades sociais [12]. Tais aplicações envolvem atividades como fazer compras em um supermercado virtual para posteriormente fazer compras em um supermercado real, preparar receitas em uma cozinha virtual e aprender a atravessar a rua, por exemplo.

Segundo [13], que elaboraram um estado da arte sobre aplicações 3D voltadas para crianças com dificuldades de aprendizagem, não há muitos projetos de pesquisa nesta área. Os autores deste trabalho utilizam o termo "dificuldades de aprendizagem" para fazer referência àquelas dificuldades cuja origem deriva de uma disfunção biológica, em vez de fatores sócio-ambientais. Eles apresentam uma aplicação denominada Virtual School, cujo público-alvo é crianças com autismo e com Síndrome de Down.

O Virtual School consiste em uma escola com diferentes ambientes onde o usuário pode aprender diversos conceitos e habilidades [13]. No ambiente virtual, o professor pode explorar com os alunos objetos presentes na escola, ensinando a sua função, bem como diferentes formas de brincar com os objetos a fim de ampliar a capacidade de imaginação das crianças. $O$ ambiente virtual também conta com atividades cujo objetivo é trabalhar relações espaciais, temporais e sociais. O Virtual School foi desenvolvido na Espanha, mas não foram publicados resultados de sua aplicação com as crianças.

No Brasil, o único sistema baseado em RV encontrado até a escrita deste trabalho, que foi testado com crianças que apresentam deficiência intelectual, mas que não foi desenvolvido especificamente para elas, foi o software RACHAKUKA [4]. E na busca por jogos desenvolvidos especificamente para crianças com deficiência intelectual, o único encontrado foi o JECRIPE [14].

O RACHAKUKA é um sistema, que utiliza técnicas de Realidade Virtual, multimídia, processamento de imagens e inteligência artificial e que permite tanto avaliar a evolução cognitiva das pessoas com necessidades educativas especiais, quanto ajudar na terapia de recuperação destas pessoas, servindo de apoio ao seu desenvolvimento cognitivo [4]. O software se baseia em jogos de memória associativa e foi validado com resultados satisfatórios, ao ser utilizado com crianças com Síndrome de Down, na faixa etária de 6 (seis) aos 12 (doze) anos em uma clínica especializada. Uma de suas limitações é o fato de pertencer a essa clínica e não estar disponível para a comunidade.

Lançado em 2010, O JECRIPE é um jogo destinado às crianças com Síndrome de Down (um tipo de Deficiência Intelectual) em idade pré-escolar, que visa estimular o desenvolvimento da percepção, coordenação motora fina e interatividade, além de outras habilidades [14]. Ele conta com tarefas que envolvem "clicar e arrastar" objetos, mover elementos para atividades específicas e até mesmo imitar gestos. O software foi testado em uma escola inclusiva, que observou que a aplicação facilita a socialização entre alunos com Síndrome de Down.

A principal limitação do JECRIPE é que, apesar de ser um jogo 3D, o mesmo não utiliza técnicas de RV e, como apresentado anteriormente, a RV possui muitas vantagens em relação a outras tecnologias. Uma dessas vantagens, por exemplo, é a possibilidade de navegar no ambiente virtual, o que não é possível no JECRIPE.

Analisando-se os trabalhos apresentados, é possível observar a ausência de aplicações de RV desenvolvidas especificamente para alunos com deficiência intelectual.

Ao se desenvolver um ambiente virtual com foco nesses alunos, as suas características devem ser consideradas, pois conforme indica [15], para que qualquer software possa atingir todo o seu potencial, é necessário projetar a interface com o usuário de forma a combinar as habilidades, expectativas e experiências dos usuários previstos. Segundo ele, uma interface projetada inadequadamente pode provocar erros por parte dos usuários e até mesmo limitá-los ao invés de ajudá-los a atingir o objetivo para o qual o sistema é usado.

Levando-se em conta as características dos indivíduos com deficiência intelectual, [9] apontam um conjunto de diretrizes para o desenvolvimento de ambientes virtuais voltados para esses indivíduos. O Quadro 1 a seguir mostra um resumo dessas diretrizes [9].

\begin{tabular}{|l|l|}
\hline Tópico & Diretriz \\
\hline Comunicação & $\begin{array}{l}\text { As instruções devem ser atômicas; textos devem } \\
\text { ser substituídos por ícones ou combinados com } \\
\text { instruções faladas. }\end{array}$ \\
\hline Navegação & $\begin{array}{l}\text { Vãos de entrada das portas devem ser mais largos } \\
\text { do que o real. }\end{array}$ \\
\hline Interação & $\begin{array}{l}\text { O uso do mouse deve ser restrito ao botão es- } \\
\text { querdo. Os dispositivos de entrada devem assegu- } \\
\text { rar a acessibilidade dos usuários. }\end{array}$ \\
\hline aprendizagem & $\begin{array}{l}\text { Se o usuário precisa selecionar itens em uma certa } \\
\text { ordem e os seleciona em uma ordem errada, ele } \\
\text { deve receber um alerta para retomar a ordem } \\
\text { correta. O uso de ícones e alertas pictóricos deve } \\
\text { ser padronizado (por exemplo: verde para "sim" e } \\
\text { vermelho para "não"). Para se adequar a pessoas } \\
\text { com diferentes níveis de habilidades, o ambiente } \\
\text { virtual deve permitir que o usuário avance para }\end{array}$ \\
\hline
\end{tabular}




\begin{tabular}{|l|l|}
\hline Acessibilidade & objetivos de aprendizagem mais avançados. \\
\hline $\begin{array}{l}\text { Embora o ambiente virtual deva ser realista, os } \\
\text { desenvolvedores devem se preocupar mais em } \\
\text { ajudar a romper as barreiras de aprendizagem } \\
\text { existentes no mundo real. }\end{array}$ \\
\hline Ética & Ambientes virtuais devem ser não-imersivos \\
\hline
\end{tabular}

Quadro 1: Diretrizes para o desenvolvimento de ambientes virtuais para a deficiência intelectual

Considerando-se as diretrizes apontadas no Quadro 1 e visto que as aplicações mencionadas anteriormente não se constituem em um AV adequado para o ensino de conceitos lógico-matemáticos para alunos com deficiência intelectual, nesse trabalho foi desenvolvido um AV denominado VirtualMat voltado especificamente para esses alunos.

\section{O aluno com Deficiência Intelectual}

\subsection{Características}

De acordo com a literatura, existem diferentes definições de Deficiência Intelectual utilizadas por importantes organizações mundiais que se tornaram referência conceitual. Uma das que se destaca é a da American Association on Intellectual and Development Disabilities (AAIDD).

Segundo a AAIDD [16], a Deficiência Intelectual é caracterizada por "limitações significativas tanto no funcionamento intelectual quanto no comportamento adaptativo, e está expresso nas habilidades conceituais, práticas e sociais. Essa deficiência deve se manifestar antes dos 18 anos".

Os indivíduos com deficiência intelectual constituem um grupo heterogêneo. Suas limitações cognitivas e adaptativas variam de pessoa para pessoa. Por esse motivo, não é possível traçar um perfil típico das pessoas com deficiência intelectual, nem características específicas padronizadas de sua personalidade ou de seu comportamento [17].

Cada aluno com Deficiência Intelectual possui necessidades educativas específicas. Mas, de um modo geral, os alunos com Deficiência Intelectual não conseguem aprender o mesmo conteúdo que os outros alunos absorvem por si só ou por métodos de ensino tradicionais [18].

Além disso, os alunos com Deficiência Intelectual encontram inúmeras barreiras nas interações que realizam com o meio para assimilar os componentes físicos do objeto de conhecimento, tais como cor, forma, textura, tamanho etc. Isso porque eles apresentam prejuízos no funcionamento, na estruturação e na re-elaboração do conhecimento [19].
O aluno sem Deficiência Intelectual consegue espontaneamente retirar informações do objeto e construir conceitos, progressivamente. Já o aluno com Deficiência Intelectual precisa exercitar sua atividade cognitiva, de modo que consiga o mesmo, ou uma aproximação do mesmo avanço. Para isso, é necessário trabalhar a abstração por meio da projeção das ações práticas em pensamento. Essa passagem deve ser estimulada e provocada, de modo que o conhecimento possa se tornar consciente e interiorizado [19].

Além dessas características, segundo [9], os alunos com deficiência intelectual têm uma tendência a se comportar passivamente diante de uma situação de aprendizagem. É necessário, portanto, estimular tal aluno a progredir nos níveis de compreensão, desafiando-o a adquirir condições de passar de um tipo de ação passiva, automática e mecânica diante de uma situação de aprendizado/experiência para o acesso e apropriação ativa do próprio saber.

É preciso oferecer situações, envolvendo ações em que o próprio aluno teve participação ativa na sua execução e/ou façam parte da experiência de vida dele.

Enquanto mediador da aprendizagem, o professor deve intervir utilizando recursos que favoreçam o desenvolvimento das funções cognitivas, fortalecendo a autonomia do aluno para opinar, escolher e tomar iniciativas, a partir de suas necessidades e motivações.

\subsection{Aprendizagem de Matemática}

Os alunos com Deficiência Intelectual, de uma forma geral, podem apresentar muitas características que interferem na construção do pensamento lógico-matemático, dentre elas destacam-se [1] [2]:

- Capacidade perceptiva: dificuldade com as relações espaciais, distâncias, e seqüenciamento. Estas dificuldades podem interferir na aquisição e demonstração de conceitos e habilidades matemáticas, tais como a estimativa de tamanho e distância e a solução de problemas.

- Pensamento abstrato: as pessoas com Deficiência Intelectual têm maior dificuldade de ter pensamento abstrato, sendo necessário que a abstração seja ensinada a elas e com maior tempo.

- Linguagem: O vocabulário referente a conceitos matemáticos não é apenas variado, mas também abstrato. Alunos com dificuldades e/ou deficiência no domínio da linguagem podem apresentar dificuldades para entender conceitos abstratos da matemática tais como: primeiro, segundo, maior que, menor que etc. 
- Memória: Muitos alunos com problemas de aprendizado têm dificuldades de lembrar-se de informações que foram apresentadas. Isto é especialmente evidente com os símbolos abstratos usados na Matemática (mais, menos, maior que etc.).

- Raciocínio: Alunos com Deficiência Intelectual apresentam dificuldades para raciocinar. Isso torna a resolução de problemas difíceis para eles. Além disso, alunos com Deficiência Intelectual podem não possuir o raciocínio abstrato necessário ao desenvolvimento de habilidades matemáticas de alto nível.

- Generalização: uma característica peculiar das pessoas com Deficiência Intelectual é a dificuldade de fazer generalizações, pois a sua aprendizagem tende a ser específica para uma situação. Eles muitas vezes não conseguem transferir o que aprenderam a um novo contexto de forma espontânea.

- Atenção: alunos com Deficiência Intelectual podem apresentar problemas de atenção significativa e baixo nível de concentração em uma situação de aprendizagem formal. Eles geralmente apresentam dificuldade na seleção, focagem e fixação de dados.

- Motivação: alguns alunos com Deficiência Intelectual não apresentam motivação espontaneamente, necessitando da mediação do professor para se envolver com as atividades. Isso ocorre principalmente com as atividades com maior grau de dificuldade e que não apresentam uma função social imediata e clara.

Os alunos com Deficiência Intelectual também apresentam grande dificuldade na utilização de conhecimentos prévios na resolução de situações-problema. Entretanto, não só essa, mas muitas de suas dificuldades podem ser minimizadas por meio de procedimentos de mediação adequados, orientados em função da demanda da atividade e das potencialidades do aluno [19].

\section{Apresentação do VirtualMat}

O VirtualMat é um ambiente virtual desenvolvido em VRML e JavaScript que tem como objetivo oferecer ao professor uma ferramenta interativa para apoiar o ensino de Matemática para alunos com Deficiência Intelectual.

O seu público-alvo são alunos com Deficiência Intelectual que estejam matriculadas entre o primeiro e o quinto anos do ensino fundamental.

\subsection{Especificação}

Os requisitos para desenvolvimento do VirtualMat foram levantados com duas profissionais da área de Educação e que atuam diretamente com a Educação Especial há mais de 15 anos. É importante ressaltar que o levantamento dos requisitos e a especificação do sistema não foram realizados em uma única etapa. Tais atividades conduziram todo o processo de desenvolvimento. De uma forma geral, os requisitos levantados mostraram que o software deveria:

R-01 (Requisito 01): oferecer à criança possibilidades de desenvolvimento do pensamento lógicomatemático por meio da ludicidade;

R-02: explorar características e categorias de objetos relacionados ao contexto social;

R-03: proporcionar variadas opções de organização cognitiva a respeito dos conceitos de classificação, discriminação, ordenação e sequenciação;

R-04: permitir que o professor trabalhe outros conceitos fundamentais da Matemática;

R-05: oferecer diferentes níveis de dificuldades atendendo à diversidade das crianças com deficiência intelectual;

R-06: contar com instruções faladas a fim de melhorar a compreensão dos usuários, especialmente aqueles que ainda não sabe ler;

R-07: apresentar um feedback às ações do usuário, com mensagens que incentive o usuário nos acertos, mas que não desestimule o usuário ao informar sobre os erros;

R-08: representar uma cidade com diversas casas, carros e um supermercado;

R-09: permitir ao usuário elaborar listas de compras, fazer compras no supermercado e guardar os produtos comprados em casa;

R-10: utilizar técnicas de Realidade Virtual nãoimersivas, sendo que a tecnologia que suporta a interação do usuário apóia-se no mouse, no teclado e no monitor (já que esses são os equipamentos disponíveis nas escolas).

De acordo com os requisitos levantados, foi elaborado o diagrama de Casos de Uso mostrado na Figura 1, com a finalidade de representar os requisitos funcionais do sistema [20]. 


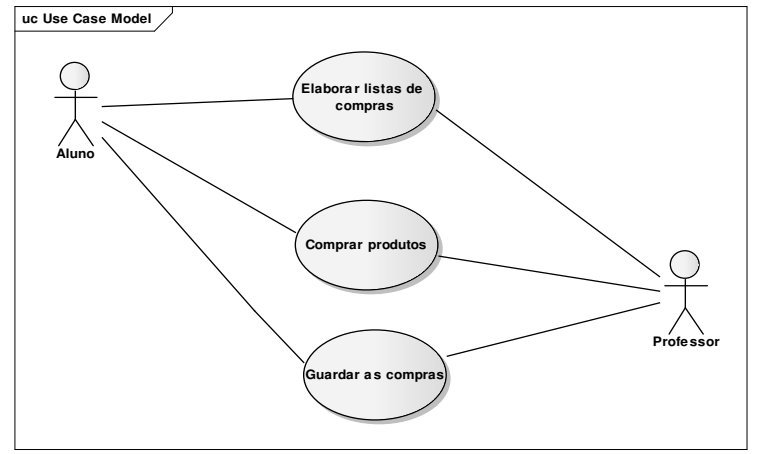

Nota: os casos de uso nas elipses são: i) elaborar listas de compras; ii) comprar produtos; e iii) guardar as compras.

Figura 1: Diagrama de Casos de uso

Conforme R-09, as funções básicas do sistema são: elaborar listas de compras, fazer compras e guardar as compras.

\subsection{Características}

O VirtualMat consiste de uma cidade onde existem, dentre outras coisas, diversas casas, prédios, carros e um supermercado (Conforme R-08). No sistema, o aluno poderá elaborar listas de compras, fazer compras num supermercado, organizar essas compras em casa, bem como explorar a utilização dos itens comprados (R-09).

As Figuras 2 e 3 mostram, respectivamente, a vista parcial do interior da casa do usuário e do supermercado.

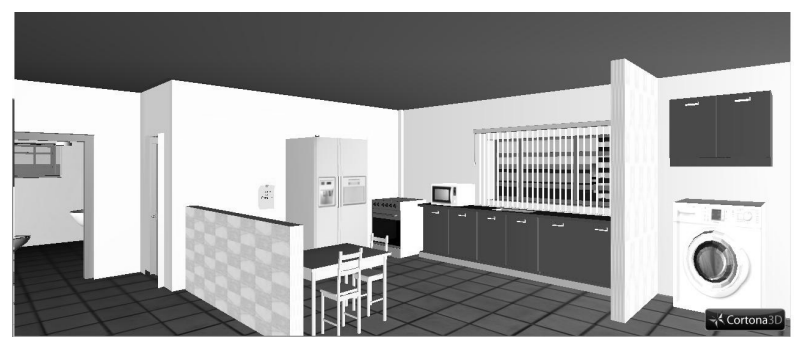

Nota: figura em escala de cinza.

Figura 2: Vista parcial da Casa do Usuário

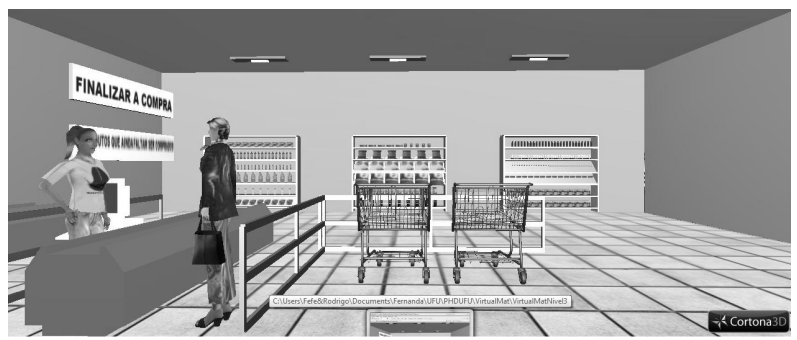

Nota: figura em escala de cinza.

Figura 3: Vista parcial do Supermercado

O VirtualMat possui 5 níveis de dificuldade de forma a atender a diversidade das crianças com deficiência intelectual (R-05). No primeiro nível, o aluno poderá conhecer a casa do usuário navegando pela mesma utilizando o mouse. A casa possui 6 cômodos: sala, cozinha, lavanderia, banheiro, quarto dos pais e quarto dos filhos. O nome de cada cômodo é ouvido quando o aluno entra no mesmo.

No segundo nível, o aluno poderá fazer uma lista de compras. Quando o aluno passa o mouse sobre um produto, o nome do produto é ouvido. Para adicionar produtos à lista, basta clicar sobre os produtos escolhidos. Caso o aluno deseje excluir um produto que esteja na lista basta clicar sobre o produto que ele sairá da lista. Após elaborar a lista de compras o aluno pode conferir os itens selecionados, podendo retornar à tela para excluir ou incluir mais produtos. A Figura 4 mostra o cenário deste nível.

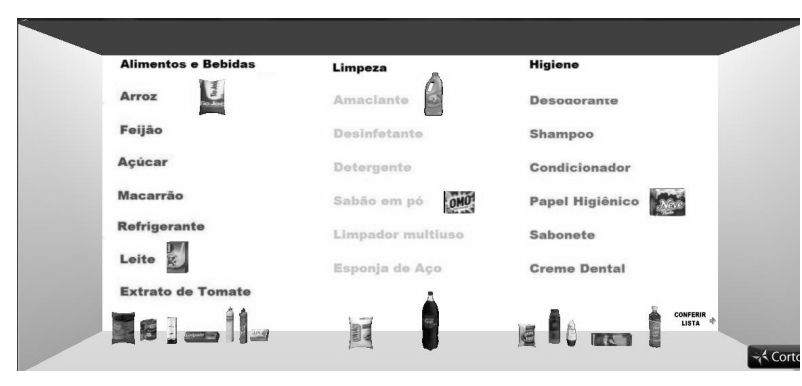

Nota: figura em escala de cinza.

Figura 4: Elaborando lista de compras

No terceiro nível, alguns produtos estarão sobre a mesa da casa do usuário. $\mathrm{O}$ aluno poderá, então, guardar os produtos nos seus respectivos lugares. O sistema foi programado de maneira que os produtos de limpeza sejam guardados no armário da lavanderia, os produtos de higiene sejam guardados no banheiro, os alimentos sejam guardados no armário da pia e as bebidas sejam guardadas na geladeira. O aluno recebe feedback do sistema tanto ao guardar um produto no lugar correto, quanto ao tentar guardar um produto no lugar incorreto. Esse feedback é dado através de mensagens faladas do tipo "Muito Bem" e "Opa! Não é aî".

O quarto nível é o nível mais completo do VirtualMat. Neste nível, há uma cidade com diversas casas (incluindo a casa do usuário dos níveis anteriores), car- 
ros, prédios e um supermercado. A Figura 5 mostra a vista parcial da cidade.

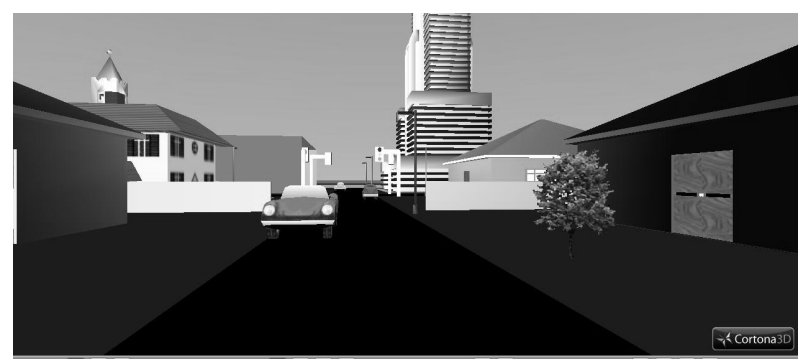

Nota: figura em escala de cinza.

Figura 5: Vista parcial da Cidade

Neste nível, o aluno poderá caminhar pela casa, abrir a porta da casa, sair pela mesma e caminhar pela cidade; o aluno também poderá elaborar uma lista de compras, fazer compras no supermercado de acordo com os produtos da lista e guardar os produtos comprados em casa.

No nível 5, o aluno poderá realizar atividades de seqüenciação. Para isso basta clicar sobre o notebook localizado em cima da mesa do quarto dos filhos. A cada sequência, o aluno deverá escolher um produto dentre as opções para completá-la. Na Figura 6, pode ser visto um exemplo de sequência a ser completada pelo aluno.

\section{QUE PRODUTO COMPLETA A SEQUENCIA?}

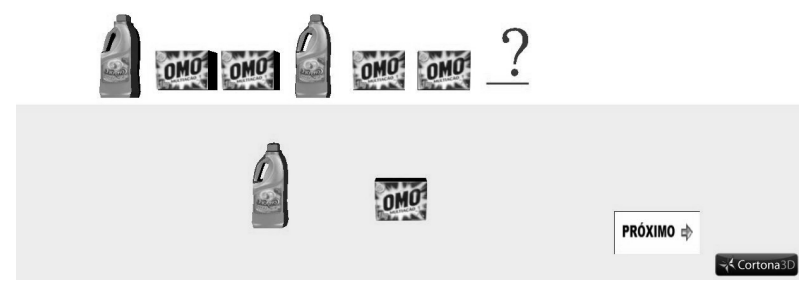

Nota: figura em escala de cinza.

Figura 6: Atividade de Seqüenciação

Atendendo aos requisitos R-01, R02, R-06, R-07 e R10, o VirtualMat é um ambiente lúdico, contém objetos e atividades relacionadas ao cotidiano dos alunos, conta com instruções faladas com o objetivo de melhorar a compreensão do usuário, oferece feedback às suas ações e utiliza técnicas de RV não-imersivas. O seu desenvolvimento também seguiu todas as diretrizes para desenvolvimento de ambientes virtuais para a deficiência intelectual apontadas por [9].

\subsection{Como explorar habilidades e conceitos lógico-matemáticos por meio do software VirtualMat}

De acordo com o requisito R-03, o VirtualMat foi desenvolvido de modo a proporcionar à criança a prática de apreender as habilidades de classificar, discriminar, seqüenciar e ordenar, possibilitando o desenvolvimento de outras habilidades como a atenção, a abstração, a memorização, a criatividade, a concentração e a percepção, essenciais à aprendizagem não só da Matemática mas também de outras disciplinas.

Atendendo ao requisito R-04, além das habilidades acima citadas, o sistema também permite que o professor trabalhe com os alunos diversos conceitos, tais como: tamanho (grande, pequeno, maior etc), posição (à direita, à esquerda, dentro, fora, ao lado etc), direção e sentido (para frente, para a esquerda, para a direita etc), relação termo a termo, tempo (antes, depois, noite, dia), capacidade (cheio, vazio, mais cheio etc), forma, cor etc.

Outro conceito importante que pode ser explorado é a idéia de quantidade. A idéia de quantidade poderá ser explorada na hora de fazer a lista de compras, na hora das compras e ao caminhar pela cidade. Para isso o professor poderá, por exemplo, perguntar ao aluno: "Quantos produtos de higiene estão na lista?" "Quantos alimentos estão na lista?" "Há mais produtos de higiene ou de limpeza?".

A fim de explorar todo o potencial da ferramenta, é importante ressaltar que a mediação do professor na utilização do sistema é fundamental. O professor tem que ser, portanto, mais do que um observador, ele deve interagir com o aluno durante a utilização do sistema, dialogando com ele, ouvindo suas dúvidas e comentários, propondo diferentes alternativas para a solução da situação-problema e procurando ouvir do próprio aluno a sua explicação sobre como ele chegou à solução dos problemas ou das atividades propostas. Assim, para que os professores possam mediar o sistema de forma adequada, foi elaborado um manual de utilização do VirtualMat contendo tanto instruções para utilização do sistema em cada nível, quanto instruções sobre como explorar noções de conceitos lógico-matemáticos durante o uso do sistema.

A seguir, serão apresentadas algumas das formas de utilização do VirtualMat na exploração de cada uma das habilidades (classificação, discriminação, sequenciação e ordenação). Ressalta-se, porém, que embora citadas separadamente, nas subseções seguintes, as habilidades acima poderão ser exploradas, simultaneamente, em cada atividade realizada no VirtualMat. Na hora de guardar as compras, por exemplo, o aluno estará classificando, sequenciando e ordenando em uma única atividade. 


\subsubsection{Classificação}

Classificar é uma operação mental básica, fundamental para formar agrupamentos, conjuntos, classes e categorias [21]. Através da classificação, o aluno aprende a identificar objetos de acordo com suas características ou atributos, tais como forma, cor, tamanho, função etc.

O conceito de classificação poderá ser explorado no VirtualMat através da elaboração de listas de compras, na compra de produtos, na organização dos produtos em casa e no trajeto entre o supermercado e a casa. Os itens poderão ser organizados por várias categorias, tais como cor, forma, tamanho e função do objeto (higiene, limpeza, alimentos, bebidas etc).

No VirtualMat, este conceito poderá ser explorado de diversas maneiras, dentre elas:

- Reconhecendo produtos semelhantes agrupando-

os quanto à sua função;

- Identificando se um elemento pertence ou não a um agrupamento;

- Descobrindo o critério utilizado numa determinada classificação;

- Estabelecendo critérios para o agrupamento de elementos;

- Agrupando seguindo um determinado critério;

- Agrupando obedecendo a mais de um critério.

\subsubsection{Discriminação}

O conceito de discriminação que se refere a identificação de um elemento diferente dentre elementos com as mesmas características poderá ser explorado em diversas situações, tais como:

- Quando o aluno estiver caminhando pela cidade pode ser solicitado que ele indique qual casa tem o telhado de determinada cor, qual tem um carro na garagem etc.;

- Pode ser solicitado que ele encontre a casa do usuário. A única casa amarela da cidade;

- Cada quarteirão tem 3 casas do mesmo modelo e uma casa de modelo diferente. O professor poderá perguntar ao aluno: "qual é a casa diferente deste quarteirão?";

- O professor poderá escolher 4 produtos de limpeza e um alimento na hora de fazer a lista de compras e então perguntar ao aluno: qual produto é diferente? Após a resposta do aluno perguntar: "porque"?

\subsubsection{Ordenação e Sequenciação}

Uma sequência pode ser vista como uma sucessão de elementos dispostos de acordo com alguma regra [21].
Nem toda sequência é ordenada. Construir sequências ordenadas (do maior para o menor, por exemplo), é um processo denominado seriação.

Segundo [21], é importante que a criança aprenda a sequienciar pessoas, objetos ou outros elementos, de acordo com algum critério, seja refletindo um modelo, um padrão ou motivo, completando uma sequência a partir de alguns elementos dados, descobrindo a regra de formação de determinada sequência ou inventando sequências com diferentes regras de formação.

O trabalho com sequências colabora para desenvolver o raciocínio lógico da criança, preparando-a para compreender a sequência dos números naturais, do sistema de numeração com seus princípio posicional, bem como dos algoritmos de adição, subtração, multiplicação, divisão etc em que os procedimentos são sequências de ações realizadas passo a passo [21].

Os conceitos de ordenação e seqüenciação poderão ser explorados ao mostrar para o aluno que o processo de fazer compras envolve um passo a passo. Primeiro devese elaborar uma lista, depois deve-se ir para o supermercado. Em seguida deve-se pegar um carrinho, escolher os produtos, passar pelo caixa, ir para a casa e por fim, guardar os produtos.

Estes conceitos também podem ser explorados pelo professor tanto na hora de fazer compras quanto na hora de guardar os produtos através de perguntas como: "Quais itens vamos guardar primeiro?" - O professor pode pedir, por exemplo que o aluno guarde todos produtos que são guardados na geladeira, depois todos os produtos que são guardados no armário da cozinha, depois no banheiro e por último na lavanderia.

A seqüenciação também poderá ser explorada no nível 5 através de exercícios que o aluno poderá realizar no notebook virtual situado no quarto dos filhos. A cada sequiência o aluno deverá escolher um produto, dentre as opções, para completá-la. O professor poderá então perguntar qual critério foi utilizado para montar a seqüência.

\subsection{Como o VirtualMat poderá minimizar as limitações do aluno com Deficiência Inte- lectual}

Conforme já discutido, os alunos com deficiência intelectual, de forma geral, podem apresentar muitas limitações. Assim, segue abaixo uma abordagem sobre como o VirtualMat poderá auxiliar na superação ou minimização de algumas destas limitações.

- Capacidade perceptiva: As dificuldades com as relações espaciais, distâncias, e seqüenciamento podem ser minimizadas ao utilizar o VirtualMat, pois durante a navegação no ambiente virtual, podem ser trabalhados conceitos como posição, direção e sentido, tamanho, seqüenciamento etc. 
- Pensamento abstrato: Ambientes Virtuais apresentam recursos superiores às outras mídias para a ilustração de conceitos abstratos, especialmente difíceis para as crianças com deficiência intelectual. Assim, o VirtualMat auxilia no desenvolvimento do pensamento abstrato do aluno ao permitir a tradução do concreto (casas, carros, embalagens de produtos e supermercado reais) para o abstrato (mundo virtual).

- Raciocínio: O VirtualMat oferece situações para que o aluno experimente dentro da escola o que pode utilizar fora dela e possibilita o envolvimento do usuário nas atividades propostas, fazendo com que estes possam experimentar controle sobre o processo de aprendizado; além disso, o VirtualMat viabiliza o aprendizado pela interação com os objetos, estimulando a curiosidade, a iniciativa e a participação ativa do aluno na construção do seu conhecimento. Estes fatores são importantes para o aluno com deficiência intelectual e estimulam o desenvolvimento do raciocínio, propiciando condições e liberdade para que ele possa construir a sua inteligência, dentro do quadro de recursos intelectuais que lhe é disponível, tornando-se agente capaz de produzir significado/conhecimento.

- Atenção: Conforme apresentado em [10], o envolvimento e o sentido de imersão, inerentes à Realidade Virtual, podem influir diretamente sobre o âmbito de atenção do usuário contribuindo para o aumento da concentração e da persistência nas tarefas.

- Motivação: Devido ao seu caráter lúdico, por ser constituído de atividades com diferentes graus de dificuldade e por referir-se a objetos que fazem parte do cotidiano do aluno, acredita-se que o VirtualMat motivará a sua participação nas atividades sugeridas. Além disso, segundo [10], a simples utilização do computador já parece atuar como fator motivador.

- Memória: Segundo [22], o tratamento de problemas de memória deve ocorrer através de ambientes estimulantes e tarefas que pedem a memorização de informações e sua posterior recuperação. Estas atividades podem ser desenvolvidas no formato de jogos que apresentem desafios com nível de dificuldade crescente. Segundo a autora, o treinamento da memória deve explorar, ainda, estratégias e situações que podem ser transferidas para as atividades da vida diária E essas são as principais características do VirtualMat, um jogo esti- mulante com diferentes níveis de dificuldades, com atividades que remetem a situações da vida diária e com situações que exigem a memorização de informações e sua recuperação, tal como o processo de compras (em que o aluno deverá se lembrar dos itens que compõem a lista). Além disso, o VirtualMat possibilita repetir as atividades várias vezes o que também facilita o processo de memorização.

- Capacidade de generalização: para alcançar a generalização é necessário explorar a memória, que realiza as atividades de recuperação das informações armazenadas, associação destas informações com a situação real e a interpretação e análise deste conjunto de informações [22]. Conforme citado no item anterior o VirtualMat permite essa exploração da memória, ampliando portanto a capacidade de generalização do aluno.

- Utilização de conhecimentos prévios na resolução de situações-problema: Conforme já foi apresentado, não só essa, mas muitas das dificuldades podem ser sensivelmente minimizadas por meio de procedimentos de mediação adequados, orientados em função da demanda da atividade e das potencialidades do aluno. O VirtualMat foi elaborado com a intenção de servir como ferramenta para a mediação da aprendizagem pelo professor.

\subsection{Validação}

Antes de ser testado, o VirtualMat foi validado por duas profissionais da área de educação que possuem mais de 15 anos de experiência na Educação Especial. Para esta etapa, o software foi detalhadamente apresentado às profissionais em duas reuniões (uma reunião com cada profissional) e, em seguida, foi pedido a cada uma delas que preenchesse um parecer estruturado informando sua avaliação. Este parecer contava com dois blocos de perguntas: Bloco A, com três questões abertas sobre os dados da profissional (formação, atuação e opinião sobre uso de recursos tecnológicos na educação especial); e Bloco B, com 11 perguntas envolvendo a opinião sobre o VirtualMat (por exemplo, se ele atende aos requisitos, se está adequado para uso junto aos alunos, dificuldades de uso, tipos de aprendizado suportados pelo sistema, benefícios para professores e alunos etc.).

Os pareceres emitidos pelas profissionais indicaram uma avaliação positiva a respeito do VirtualMat. Segundo o parecer de uma delas, que possui vasta experiência na Educação Especial (mais de 16 anos), atuando com todos os tipos de deficiência, o VirtualMat "é composto por atividades coerentes com a realidade vivenciada 
pelos alunos em seu cotidiano familiar e para o aluno com Deficiência Intelectual esse é um aspecto extremamente importante a ser considerado."

Além disso, segundo o mesmo parecer, o VirtualMat incentiva a aprendizagem dos alunos com Deficiência Intelectual, possibilitando dessa forma, mudanças de comportamento e elevação da auto-estima, tanto do aluno como do professor que conseguirá ver resultados efetivos em sua atuação pedagógica.

De acordo com a outra profissional, que trabalha com a educação especial desde 1993, "o programa VirtualMat, se configura como mais uma oportunidade de utilização da tecnologia digital (computador e software/ internet), enquanto recurso pedagógico na aquisição (aluno) e desenvolvimento (professor) de conceitos lógico-matemáticos imprescindíveis no processo de aprendizagem escolar". Ela também considera que "o sistema está suficientemente adequado para a aplicação com os alunos, uma vez que possui uma conotação de lúdico, por ser considerado um jogo enquanto proposta pedagógica".

Desta forma, a consulta aos pareceres das profissionais indicou que o VirtualMat já estava adequado para aplicação em escolas junto a alunos e professores. Os procedimentos relacionados com a utilização do software nas escolas e o seu teste são descritos na seção seguinte.

\section{Aspectos metodológicos}

Conforme apresentado a seguir, o VirtuaMat foi testado em uma escola municipal por 9 alunos que apresentam Deficiência Intelectual juntamente com 2 professores do Atendimento Educacional Especializado. Esses alunos possuem entre 11 e 22 anos (a média da idade é de 15 anos) e estão matriculados entre o primeiro e quinto anos do ensino fundamental.

O método utilizado para avaliar os resultados obtidos com a utilização do VirtualMat apresentou uma abordagem tanto qualitativa quanto quantitativa. Para a etapa quantitativa, foi desenvolvido um questionário sobre as habilidades e conhecimentos apresentados pelos alunos; sua elaboração contou com a opinião de uma profissional com mais de 15 anos de experiência com alunos da educação especial.

O questionário possui 29 questões, sendo cinco a respeito de informações gerais sobre o aluno (idade, sexo, ano que está cursando etc), oito a respeito do perfil do aluno (se o aluno é calmo ou agitado, se o mesmo consegue interagir com os colegas, se tem dificuldades de linguagem etc) e dezesseis a respeito das habilidades e conceitos lógico-matemáticos (se o aluno tem noção de sequênciação, classificação, ordenação, se domina os conceitos de forma, tamanho, posição etc). Essa última parte do questionário utilizada para quantificar os construtos referentes às habilidades e conceitos lógicomatemáticos dos alunos foi elaborada com base em uma revisão da literatura sobre o ensino de matemática, já que estas são as habilidades e conceitos explorados pelo VirtualMat.

O objetivo do desenvolvimento do questionário foi avaliar o conhecimento dos alunos antes e depois da utilização do software. Vale destacar que o questionário foi respondido pelos professores do Atendimento Educacional Especializado que trabalham diretamente com alunos que apresentam Deficiência Intelectual. Para cada habilidade ou conceito os professores deram uma pontuação com base em uma escala que varia de 1 a 5, em que 1 representa "Discordo Fortemente" e 5 representa "Concordo Fortemente".

Em um primeiro contato com a escola, foi solicitado que os professores respondessem aos questionários sobre os alunos que iriam participar da pesquisa. Em seguida, deu-se início a etapa de utilização do VirtualMat, com encontros periódicos, durante o período de 3 meses (Junho/2011, Agosto/2011 e Setembro/2011). Após a utilização do software pelos alunos, os questionários foram novamente aplicados aos professores (não sendo permitida a consulta ao primeiro questionário respondido), visando quantificar o conhecimento dos alunos a respeito de aspectos lógico-matemáticos após o uso do software.

A comparação entre as respostas médias dos questionários foi formalizada com base no teste $t$ para diferença entre médias, sendo os dados considerados como amostras relacionadas (ou dependentes [23]), pois cada aluno produz um par de valores de dados (nota nas habilidades antes e depois do uso do software), permitindo sua comparação média, entre habilidades e entre alunos. O nível de significância foi considerado como $5 \%$, pois é este o parâmetro comumente adotado em trabalhos acadêmicos que envolvem testes estatísticos [24]. A hipótese principal foi de que a nota média das habilidades após o uso do software seria maior do que a nota média das habilidades antes da utilização do software.

Na etapa qualitativa, foi realizada a observação que, conforme descrevem [25], consiste em um elemento básico da investigação científica, utilizado na pesquisa de campo; este método "não consiste apenas em ver ou ouvir, mas também em examinar fatos ou fenômenos que se deseja estudar". Ainda segundo os citados autores, este método obriga o pesquisador a um contato mais direto com a realidade analisada, o que é coerente com o objetivo de se testar um software por meio da análise da interação entre ele e seus usuários. Para tornar mais formal o processo de observação, foi realizado, metodicamente, o registro em um bloco de anotações dos fatos 
ocorridos durante a aplicação do software. Esse conjunto de anotações foi então posteriormente reunido para relato no presente estudo, buscando-se auxiliar a discussão teórica com a prática observada e os resultados dos testes estatísticos.

\section{Resultados}

A Figura 7, a seguir, descreve os resultados para a análise das habilidades médias dos alunos antes e após a utilização do VirtualMat. As duas últimas colunas se referem às médias gerais, antes e após o uso do sistema.

Conforme indica a citada figura, as notas médias dos alunos após a utilização do software, para todas as habilidades levadas em consideração, foram maiores do que as notas médias antes da utilização do VirtualMat. Essa diferença, para a maioria das habilidades (inclusive para a média geral), foi estatisticamente significativa ao nível de $5 \%$. Há de se destacar que, para a maior parte das habilidades cuja diferença não foi estatisticamente significativa, os alunos já possuíam relativamente uma nota alta na primeira avaliação; mesmo assim, houve aumento em suas notas.

Já a Figura 8 descreve os resultados para a análise das médias obtidas por cada aluno antes e após a utilização do VirtualMat, podendo-se verificar que as notas médias de todos os alunos após a utilização do software foram maiores do que as notas médias antes de sua utilização. Essa diferença, para todos os casos, foi estatisticamente significativa, ao nível de 5\%.

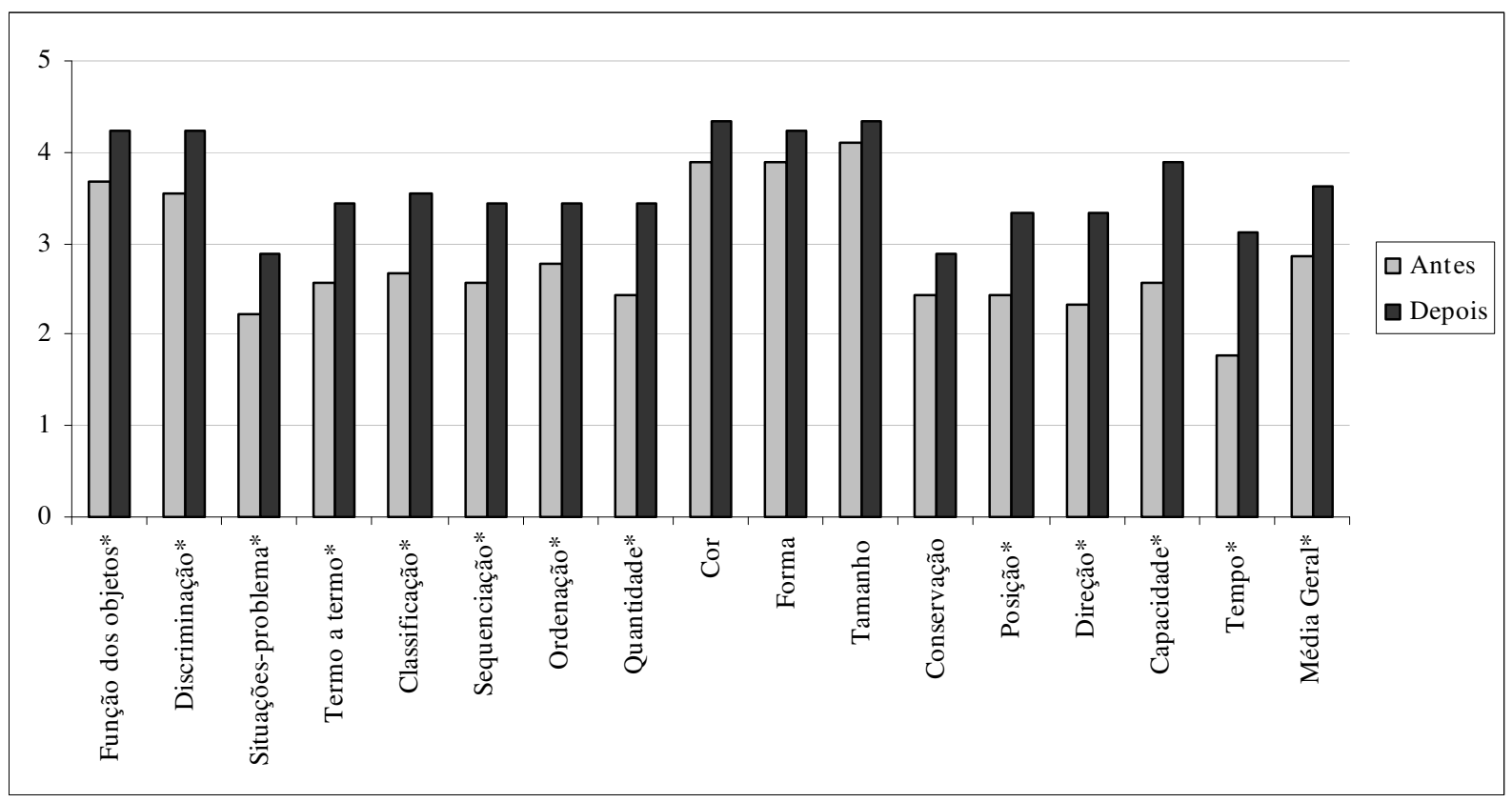

Notas: as habilidades destacadas referem-se aos 16 itens presentes no questionário, que tiveram por objetivo medir o conhecimento dos alunos antes e após o uso do VirtualMat. Para cada habilidade, tem-se no gráfico sua respectiva nota média dos 09 alunos antes e depois do uso do VirtualMat. *As habilidades cujo teste de diferença de médias foi significativo ao nível de 5\% estão acompanhadas de um asterisco em sua denominação.

Figura 7: Habilidades médias para o grupo de alunos analisados 


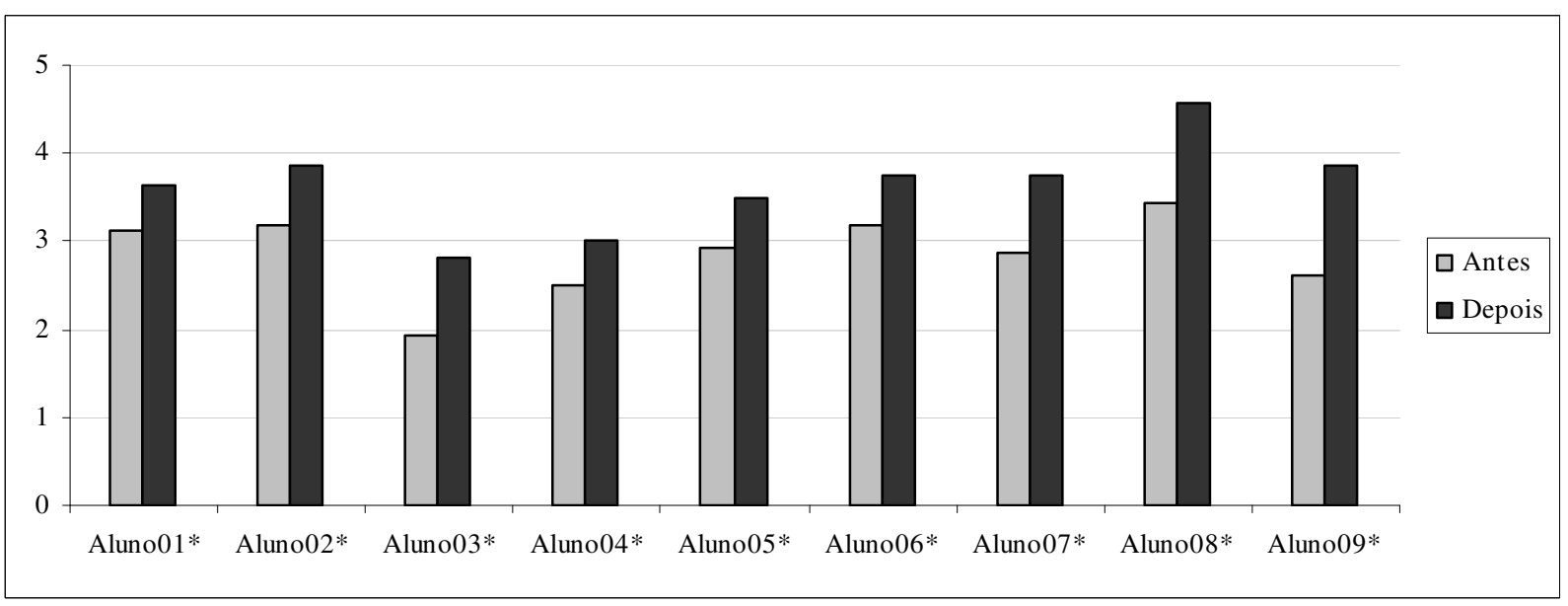

Notas: as barras do gráfico se referem à nota média por aluno para as 16 habilidades. *Os alunos cujo teste de diferença de médias foi significativo ao nível de 5\% estão acompanhados de um asterisco em sua denominação.

Figura 8: Média, por aluno, das habilidades antes e após o uso do software

Para complementar as informações disponíveis nas Figuras 7 e 8, foi elaborada a Tabela 1, que mostra a estatística descritiva para as notas médias tanto para os 9 alunos quanto para as 16 habilidades, antes e após o uso do VirtualMat. Destaca-se que os valores para a média, mínimo e máximo dos 9 alunos aumentou após o uso do VirtualMat, assim como foi o caso das 16 habilidades, corroborando as análises dos gráficos já realizadas até o momento.

\begin{tabular}{lccccc}
\hline Notas Médias & n & Média & Desv. Pad. & Mínima & Máxima \\
\hline Alunos Antes & 09 & 2,868 & 0,455 & 1,938 & 3,438 \\
Alunos Depois & 09 & 3,639 & 0,512 & 2,813 & 4,563 \\
Habil. Antes & 16 & 2,868 & 0,708 & 1,778 & 4,111 \\
Habil. Depois & 16 & 3,639 & 0,514 & 2,889 & 4,444 \\
\hline
\end{tabular}

Tabela 1: Estatística descritiva para as notas médias dos alunos e das habilidades, antes e após o uso do VirtualMat

As evidências apresentadas nas Figuras 7 e 8, complementadas pela Tabela 1, apontam indícios de que a utilização do VirtualMat apresentou uma contribuição significativa para que os alunos aprendessem/fixassem conceitos lógico-matemáticos que, pelos métodos tradicionais de ensino, não tinham ainda sido fixados.

Com base nas anotações decorrentes das observações, constatou-se que os alunos apresentaram uma dificuldade inicial ligada ao uso do mouse para navegação no ambiente. No entanto, essa dificuldade foi superada por todos os alunos na medida em que eles tiveram mais contato com o software. Já com relação às atividades propostas no sistema, os alunos não apresentaram dificuldades. Segundo os professores, os alunos conseguiram interagir bem com o sistema por se tratar de algo que trabalha com assuntos referentes ao seu dia a dia, como fazer compras, andar pela rua, organizar as compras em casa etc. Além disso, conforme uma das profissionais que validou o sistema, suas informações são precisas, as imagens tridimensionais são nítidas e de fácil acessibilidade e o nível de exigência das atividades propostas pode ser considerado razoável em função das limitações cognitivas apresentadas por esses alunos.

Também foi observado que tanto os professores quanto os alunos se sentiram motivados para utilizar o sistema, pois os alunos demonstram, segundo os professores, grande interesse por atividades realizadas no computador.

Com base nestas constatações, entende-se que o VirtualMat contribui com a aprendizagem dos alunos ao permitir o desenvolvimento do pensamento lógicomatemático de maneira lúdica e ativa.

\section{Considerações Finais}

Este artigo apresentou um ambiente virtual educativo, denominado VirtualMat, que tem como objetivo auxiliar o professor a explorar noções básicas de conceitos lógico-matemáticos com alunos que apresentam Deficiência Intelectual.

O software foi validado por profissionais da área de 
educação especial e testado por alunos com Deficiência Intelectual matriculados em uma escola inclusiva. A aplicação da ferramenta foi avaliada considerando-se uma abordagem tanto quantitativa quanto qualitativa.

Os resultados apontam que o VirtualMat contribui significativamente para o desenvolvimento do pensamento lógico-matemático dos alunos com Deficiência Intelectual. Essas evidências indicam que a RV possui um papel relevante no processo de aprendizagem de alunos com Deficiência Intelectual.

As características relacionadas aos sistemas de RV (alto nível de interação, resposta realística às ações do usuário, envolvimento e possibilidade de imersão - [5]) pareceram representar fatores decisivos no processo de aprendizagem de alunos com Deficiência Intelectual. Isso corrobora a relevância da RV para fins educacionais, já destacado por outros autores [8] [6] [22], sendo que as evidências deste trabalho contribuem com essa discussão por mostrar resultados empíricos sobre sua aplicação para alunos com Deficiência Intelectual.

Se for levado em conta que esses alunos possuem diferentes estilos cognitivos [6], aponta-se também o nível de adequação que a RV mostrou nos casos estudados neste trabalho, o que vem também a corroborar com a revisão da teoria sobre o assunto [6], contribuindo por possuir evidências empíricas de uma outra realidade (ensino de alunos com necessidades especiais).

Se um dos desafios da TI para os próximos anos seria o de contribuir com o processo de educação, a utilização da RV parece ter papel fundamental no alcance dessa meta. A TI não teria sua aplicação se não houvesse pessoas interessadas em utilizá-la, e percebe-se que o dia-adia das pessoas pode ser cada vez mais melhorado com a sua utilização.

Pretende-se ainda utilizar o software em outras escolas, com o objetivo de ampliar a amostra de alunos pesquisados e realizar novas análises estatísticas para avaliar o potencial da realidade virtual como tecnologia assistiva para alunos com Deficiência Intelectual.

Enfim, espera-se que o VirtualMat possa contribuir de forma ímpar com o processo de ensino-aprendizagem dos alunos com Deficiência Intelectual, facilitando a apreensão de conceitos e habilidades que, por diversos motivos, não são apreendidos por esses alunos de forma convencional (quadro e giz).

Como sugestões para novas pesquisas, indica-se a análise dos benefícios e contribuições que a RV pode gerar no processo de ensino-aprendizagem de outras disciplinas, pois ela permite a elaboração de um ambiente interativo virtual e tridimensional que pode ser explo- rado também em outros contextos.

\section{Referências}

[1] P. Westwood. What teachers need to know about students with disabilities. ACER Press, 2009.

[2] M. E. Little. Teaching Mathematics: Issues and solutions. Teaching Exceptional Children Plus, 6(1): 1-15, 2009.

[3] P. Westwood. Commonsense Methods for Children with Special Educational Needs. Routledge, 6ed., 2011.

[4] I. Oliveira; E. Soeira; Software RACHAKUKA: definindo uma tecnologia assistiva para deficientes mentais. Revista EDaPECI - Educação a Distância e Práticas Educativas Comunicacionais e Interculturais. 2:83-89, 2009.

[5] C. Kirner; R. A. Siscoutto. Fundamentos de Realidade Virtual e Aumentada. In: (org.). Realidade Virtual e Aumentada: Conceitos, Projetos e Aplicações. Livro do IX Symposium on Virtual and Augmented Reality. Editora SBC, Porto Alegre, 2007.

[6] F. Mantovani. VR Learning: Potential and Challenges for the Use of 3D Environments in Education and Training. In: Towards CyberPsychology: Mind, Cognitions and Society in the Internet Age. G. Riva; C. Galimberti (Eds.) Amsterdam, IOS Press, p. 208-226, 2003.

[7] V. Marins; C. Haguenauer; G. Cunha. Realidade Virtual em Educação: Criando Objetos de Aprendizagem com VRML. Colabor@ - A Revista Digital da CVA- RICESU. 4(15), 2007.

[8] J. T. Bell; H. S. Foglerl. The Investigation and Application of Virtual Reality as an Educational Tool. In Proceedings Of The American Society For Engineering Education Annual Conference, Anaheim, CA, 1995.

[9] P. J. Standen; D. J. Brown. Virtual reality and its role in removing the barriers that turn cognitive impairments into intellectual disability. Virtual Reality. Springer. 2006 pp. 241-252.

[10] M. S. Guimarães. Avaliação do Potencial de Utilização de um Ambiente Virtual 3D para a Prática de Exercícios de Matemática por Crianças com Transtorno de Déficit de Atenção e/ou 
Hiperatividade. Tese (Doutorado). Universidade Federal do Rio de Janeiro, 2006.

[11] C. S. Lányi et al. Virtual Reality in Special Needs Early Education. The International Journal of Virtual Reality, 5(4): 55-68, 2006.

[12] P. J. Standen; D. J. Brown. Virtual Reality in the Rehabilitation of People with Intellectual Disabilities: Review. Cyberpsychology \& Behaviour, 8(3), pp. 272-282, 2005.

[13] L. Vera et al. Computer graphics applications in the education process of people with learning difficulties. Computers \& Graphics 31 pp. 649658, 2007.

[14] A. Brandão et al. Semiotic Inspection of a game for children with Down syndrome. 2010. In Proceedings of IX Brazilian Symposium on Computer Games and Digital Entertainment, November 2010.

[15] I. Sommerville. Engenharia de Software. 8. ed. São Paulo: Addison-Wesley, 2003. 552p.

[16] R. L Schalock; S. A. Borthwick-Duffy; V. J. Bradley et al. Intellectual Disability: Definition, Classification, and Systems of Supports. AAIDD, 11ed, 2010.

[17] MEC/SEESP. Programa de Capacitação de Recursos Humanos do Ensino Fundamental: Deficiência intelectual. Série: Atualidades Pedagógicas 3. Brasília: Ministério da Educação, Secretaria de Educação Especial, 1997.

[18] C. Dechichi. Transformando o ambiente da sala de aula em um contexto promotor do desenvolvimento do aluno deficiente mental. Tese (Doutorado). Universidade Católica de São Paulo. 2001.

[19] C. A. M. Batista; M. T. E. Mantoan. Educação Inclusiva: Atendimento Educacional Especializado para a Deficiência Intelectual. Brasília: MEC/SEESP, 2006.

[20] E. Medeiros, E. Desenvolvendo Software com UML 2.0 Definitivo. São Paulo: Pearson Makron Books, 2004.

[21] L. R. Dante. Didática da Matemática na PréEscola. São Paulo: Editora Ática, 1996.

[22] R. M. E. M. da Costa. Ambientes virtuais na Reabilitação Cognitiva de pacientes neurológicos e psiquiátricos. 149p. Tese de Doutorado. Universidade Federal do Rio de Janeiro, 2000.
[23] D. R. Anderson; D. J. Sweeney; T. A. Williams; T. A. Estatística Aplicada à Administração e Economia. $2^{\mathrm{a}}$ ed.. São Paulo: Cengage Learning, 2007.

[24] J. F. Hair Jr. et al. Fundamentos de métodos de pesquisa em Administração. Tradução de Lene Belon Ribeiro. Porto Alegre: Bookman, 2005.

[25] M. de A. Marconi; E. M. Lakatos. Técnicas de

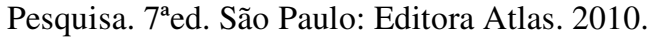

